\title{
NMR structure of the apoB mRNA stem-loop and its interaction with the $C$ to $U$ editing APOBEC1 complementary factor
}

\author{
CHRISTOPHE MARIS, ${ }^{1}$ JAMES MASSE, ${ }^{1}$ ANN CHESTER,${ }^{2}$ NAVEENAN NAVARATNAM, ${ }^{2}$ and \\ FRÉDÉRIC H.-T. ALLAIN ${ }^{1}$ \\ ${ }^{1}$ Institute for Molecular Biology and Biophysics, ETH Hönggerberg, HPK, CH-8093 Zürich, Switzerland \\ ${ }^{2}$ RNA Editing Group, MRC Clinical Sciences Centre, Faculty of Medicine, Imperial College, Hammersmith Campus, London W12 0NN, UK
}

\begin{abstract}
We have solved the NMR structure of the 31-nucleotide (nt) apoB mRNA stem-loop, a substrate of the cytidine deaminase APOBEC1. We found that the edited base located at the $5^{\prime}$ end of the octa-loop is stacked between two adenosines in both the unedited (cytidine 6666) and the edited (uridine 6666) forms and that the rest of the loop is unstructured. The 11-nt "mooring" sequence essential for editing is partially flexible although it is mostly in the stem of the RNA. The octa-loop and the internal loop in the middle of the stem confer this flexibility. These findings shed light on why APOBEC1 alone cannot edit efficiently the cytidine 6666 under physiological conditions, the editing base being buried in the loop and not directly accessible. We also show that APOBEC1 does not specifically bind apoB mRNA and requires the auxiliary factor, APOBEC1 complementary factor (ACF), to edit specifically cytidine 6666. The binding of ACF to both the mooring sequence and APOBEC1 explains the specificity of the reaction. Our NMR study lead us to propose a mechanism in which ACF recognizes first the flexible nucleotides of the mooring sequence (the internal loop and the $3^{\prime}$ end octa-loop) and subsequently melts the stem-loop, exposing the amino group of the cytidine 6666 to APOBEC1. Thus, the flexibility of the mooring sequence plays a central role in the RNA recognition by ACF.
\end{abstract}

Keywords: RNA editing; apoB mRNA; APOBEC1; ACF; NMR structure

\section{INTRODUCTION}

Cytidine (C) to uridine (U) editing of apoB100 apolipoprotein mRNA at the nucleotide position 6666 converts the genomically encoded glutamine codon 2153 (CAA) into a premature termination codon (UAA) that generates the carboxyl-terminal truncated apoB48 protein (Chen et al. 1987; Powell et al. 1987). The apoB mRNAs in mammals are extensively edited in the small intestine but remain unedited or partially edited in the liver (Powell et al. 1987; Greeve et al. 1993). ApoB-48 is colinear with the N-terminal half of apoB-100, but lacks the C-terminal domain required for interaction with the low-density lipoprotein (LDL) receptor. As a result, lipoprotein particles containing apoB-48 are directed to a different metabolic pathway and undergo more rapid catabolic clearance than particles containing the full-length apoB-100. The amount of edited apoB mRNA is

Reprint requests to: Frédéric H.-T. Allain, Institute for Molecular Biology and Biophysics, ETH Hönggerberg HPK D11.2, CH-8093 Zürich, Switzerland; e-mail: allain@mol.biol.ethz.ch; fax: 41-(0)-1-63-31294.

Article and publication are at http://www.rnajournal.org/cgi/doi/ 10.1261/rna.7190705. an important determinant in the LDL and VLDL metabolism (Teng et al. 1994; Innerarity et al. 1996).

ApoB mRNA editing is an intranuclear event occurring posttranscriptionally coincident with splicing and polyadenylation (Lau et al. 1991). The editing complex (editosome) recognizes the defined sequence elements flanking the edited cytidine in apoB mRNA. The catalytic subunit of the editing complex is APOBEC1 (apoB mRNA-editing cytidine deaminase subunit-1) (Teng et al. 1993; Hadjiagapiou et al. 1994; Yamanaka et al. 1994; Nakamuta et al. 1995). APOBEC1 is a homodimeric zinc-containing cytidine deaminase (Lau et al. 1991; Yamanaka et al. 1994; MacGinnitie et al. 1995; Navaratnam et al. 1995) that has been identified in several species (Teng et al. 1993; Hadjiagapiou et al. 1994; Yamanaka et al. 1994; Nakamuta et al. 1995). Homology modeling of APOBEC1 onto the crystal structure of Escherichia coli cytidine deaminase (ECCDA) suggested that both enzymes are related in tertiary and quaternary structure (Navaratnam et al. 1998). The catalytic activity of APOBEC1 is thermostable with an optimal RNA editing at $45^{\circ} \mathrm{C}$ (Chester et al. 2004). In vivo, the editosome is composed of many other auxiliary proteins that regulate the enzymatic activity. These proteins range in their molecular masses from 40 to $300 \mathrm{kDa}$ (Lau et al. 1991; Na- 
varatnam et al. 1993; Teng et al. 1993; Driscoll and Zhang 1994; Giannoni et al. 1994; Yamanaka et al. 1994; Navaratnam et al. 1995). To efficiently edit apoB mRNA under physiological conditions, APOBEC1 needs APOBEC1 complementation factor (ACF) (Mehta et al. 2000) that belongs to the hnRNP family. At physiological temperatures, ACF stabilizes an altered form of the RNA substrate that forms spontaneously at higher temperatures (Chester et al. 2004). While APOBEC1 is mainly expressed in the small intestine, ACF is widely expressed in several tissues and therefore plays a general role in mRNA metabolism (Mehta et al. 2000). The 63.4-kDa ACF contains three nonidentical RNA recognition motifs (RRMs), an arginine-rich domain, and a putative double-stranded RNA binding domain. In the editing complex, ACF binds both apoB mRNA and APOBEC1, positioning the enzyme for site-specific deamination (Mehta et al. 2000). Recently, two novel mRNA transcripts alternatively processed from the ACF pre-mRNA were identified. They encode the 43- (ACF43) and $45-\mathrm{kDa}$ (ACF45) editosomal proteins colinear with the $\mathrm{N}$-terminal part of ACF protein that are expressed only in the liver and the small intestine. The recombinant ACF45 can displace both ACF and ACF43 from the "mooring" sequence but interacts weakly with APOBEC1. In contrast, ACF43 binds strongly to APOBEC1 but weakly to the mooring sequence (Sowden et al. 2004). ACF variants might compete with one another for APOBEC1 and apoB mRNA binding and thereby contribute to the regulation of apoB mRNA editing. Another protein, GRY-RBP (glycine-argininine-tyrosine-rich RNA-binding protein), also belonging to the hnRNP R family and having $50 \%$ amino acid sequence similarity to ACF was found to bind apoB mRNA and to competitively inhibit editing in vitro (Blanc et al. 2001b).

The minimal apoB mRNA sequence competent for editing is 26 nucleotides (nt) long (Davies et al. 1989) and is highly conserved from marsupial to man (Teng and Davidson 1992; Anant et al. 1995). In addition to the editing site, this sequence contains three other cis-acting elements required for site-specific deamination of apoB mRNA (Shah et al. 1991; Backus and Smith 1992; Driscoll et al. 1993). The first element is an 11-nt-long sequence (6671-6681), referred to as the mooring sequence, located downstream of the edited C6666, and it is absolutely indispensable for editing (Bostrom et al. 1989; Davies et al. 1989; Driscoll et al. 1989; Chen et al. 1990; Shah et al. 1991). The region between C6666 and the mooring sequence called the "spacer element" can vary in length from 2 to 8 nt with an optimal length of $4 \mathrm{nt}$ (Driscoll et al. 1993). The third sequence is the AU-rich "efficiency sequence," located upstream of C6666, modulating the yield of the editing reaction. Outside this essential 26-nt editing cassette, two other RNA sequences were identified, a $5^{\prime}$ efficiency element (66096628) and a $3^{\prime}$ efficiency element (6717-6747) that both enhance in vitro editing at physiological levels (Hersberger and Innerarity 1998). The conserved sequences around the edited cytidine (6662-6687) were shown to form a stemloop secondary structure where the editing site is located in an octa-loop (Richardson et al. 1998). This stem-loop plays an important role in the RNA recognition by the editing factors (Bostrom et al. 1989; Davies et al. 1989; Driscoll et al. 1989; Chen et al. 1990; Shah et al. 1991). Another secondary structure has been suggested in which the mooring sequence and the $3^{\prime}$ efficiency element form a doublestranded stem, the edited cytidine being located in a singlestranded region and not in a stem-loop (Hersberger et al. 1999). However, no further experimental evidence for this alternative secondary structure is available to date.

In the present study, we have determined the solution structures of the unedited (C6666) and edited (U6666) 31nt apoB human mRNA stem-loop containing four of the conserved cis-acting elements using heteronuclear NMR spectroscopy. To understand the recognition of the RNA stem-loop by ACF, we have investigated by NMR the interaction of apoB mRNA with a $34-\mathrm{kDa}$ fragment of ACF (ACF34) containing the three RRMs that are essential for RNA binding and APOBEC1 complementation (Blanc et al. 2001a). Furthermore, we performed biochemical experi-

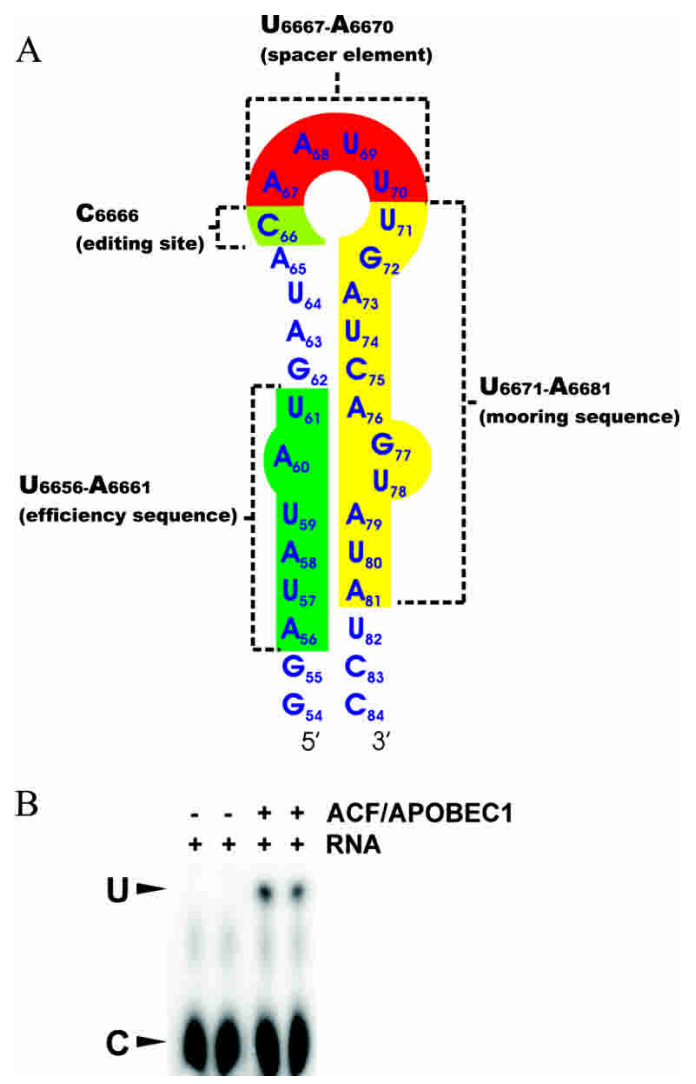

FIGURE 1. (A) Secondary structure of the 31-nt sequence of the human apoB mRNA studied here. The different cis-acting elements involved in cyditine C6666 editing are colored. $(B)$ Editing assays of the 31-nt apoB mRNA stem-loop used for our structural studies. "U" indicates that the RNA is edited and " $\mathrm{C}$ " that it remains unedited (two assays were performed for each condition, "+" with ACF/APOBEC1 and "_" without). 
A
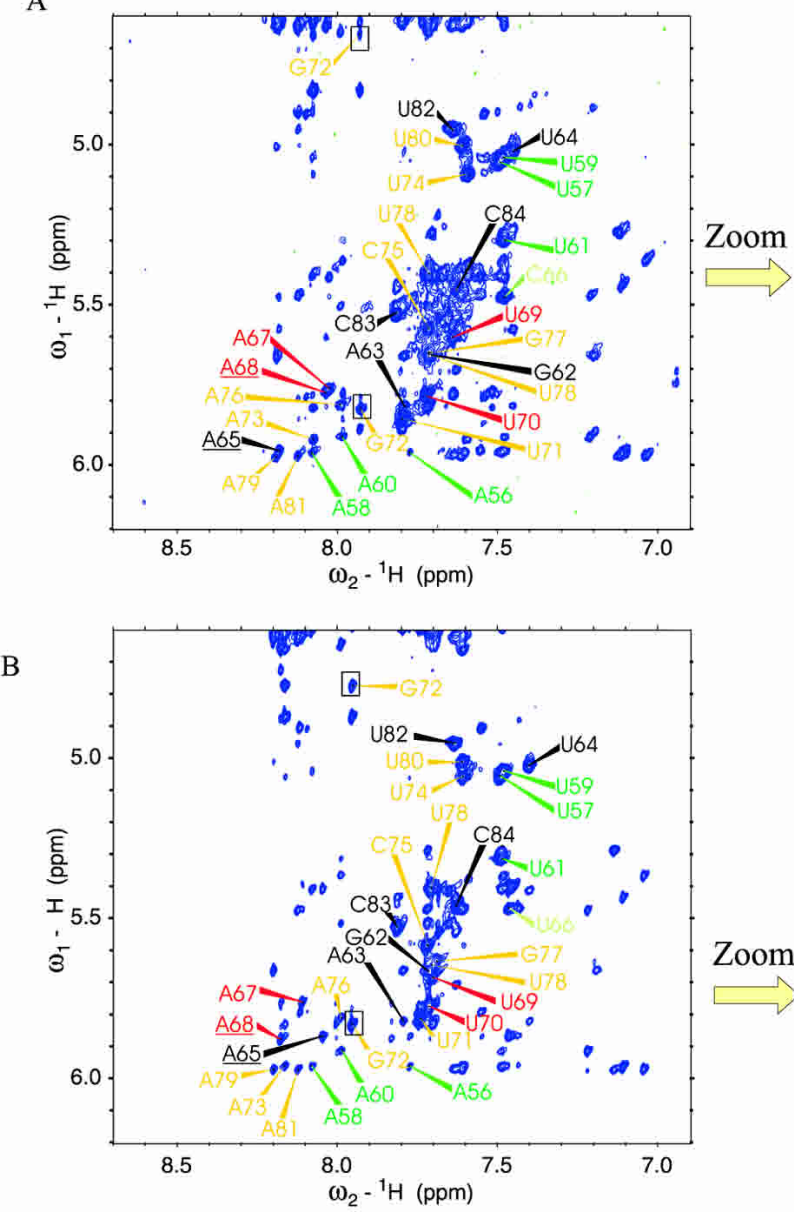

Zoom
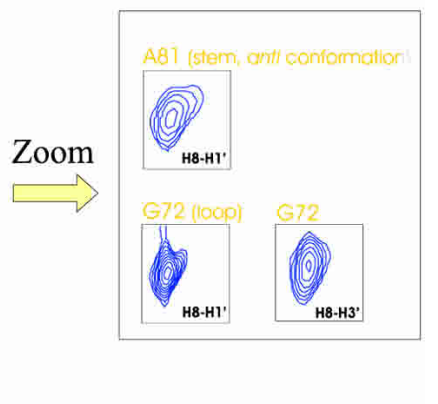

FIGURE 2. Section of a $2 \mathrm{D}\left({ }^{1} \mathrm{H}-{ }^{1} \mathrm{H}\right)$ NOESY $\left(\tau_{\mathrm{m}}=250 \mathrm{msec}\right)$ of the $31-\mathrm{nt}$ apoB mRNAs unedited $(A)$ and edited $(B)\left(\mathrm{H}^{\prime}\right.$-aromatic region) recorded at $30^{\circ} \mathrm{C}$ on a $900-\mathrm{MHz}$ spectrometer. The intranucleotide NOEs ( $\mathrm{H} 8-\mathrm{H} 1^{\prime}$ for purines and $\mathrm{H} 5-\mathrm{H} 6$ for pyrimidines) are indicated in yellow (mooring sequence), green (efficiency sequence), red (spacer element), and black (others). The two rectangular boxes in each spectrum show G72 H8-H1' and H8-H3' cross-peaks that are indicative of G72 experiencing a syn-anti exchange. A65 and A68 from the octa-loop have the largest chemical shift changes between the unedited and edited RNAs (their labels are underlined). Several critical NOE cross-peaks are shown in a separate box for clarity (see text).

ments in order to further identify the RNA binding sites of ACF and APOBEC1 on ApoB mRNA.

\section{RESULTS AND DISCUSSION}

\section{NMR structures of the unedited and edited forms of APOBEC1 substrate}

We have determined the structures of the human apoB mRNA stem-loop in its "unedited form" (C6666) and "edited form" (U6666). For convenience, we have used the last two digits of the GenBank numbering to describe our results (for instance, C66 refers to C6666). The 31-nt RNA sequence that we studied includes the main cis-acting elements, namely, the editing site C66 (or U66), the spacer element (67-70), the mooring sequence (71-81) and a part of the efficiency sequence (Fig. 1A). As shown in Figure 1B, this 31-nt substrate can be specifically edited in vitro by both purified APOBEC1 and ACF. Two additional G-C base pairs were added to the end of the stem to optimize the yield of RNA synthesis by in vitro transcription.

Nearly complete ${ }^{1} \mathrm{H},{ }^{13} \mathrm{C}$, and ${ }^{15} \mathrm{~N}$ resonance assignments were obtained for both RNAs using homonuclear $\left({ }^{1} \mathrm{H}-\right.$ $\left.{ }^{1} \mathrm{H}\right)$ and heteronuclear $\left({ }^{1} \mathrm{H}_{-}{ }^{13} \mathrm{C}\right.$ and ${ }^{1} \mathrm{H}-$ $\left.{ }^{15} \mathrm{~N}\right)$ NMR experiments. For both RNAs, the aromatic to anomeric region of the $2 \mathrm{D}{ }^{1} \mathrm{H}-{ }^{1} \mathrm{H}$ NOESY is shown in Figure 2 with the resonance assignments indicated. A high number of NOE-derived distance constraints were collected in order to calculate the structures of both RNAs (Table 1). The resulting ensembles of structures show a very similar fold for both RNAs characterized by some structured elements (around C66 or U66) and some more flexible elements (most of the mooring sequence). The structural features of the four cisacting elements are described separately and their implications for the RNA recognition by ACF and APOBEC1 are discussed below.

\section{Overall description of the structures}

A total of 469 and 466 upper-limit interproton distance restraints were obtained for the unedited (C66) and edited (U66) apoB mRNA, respectively (Table 1). In both RNAs, G72 was found in fast exchange between syn and anti conformations, since medium to strong NOE correlations for both $\mathrm{G} 72 \mathrm{H} 8-\mathrm{H}^{\prime}$ and $\mathrm{H} 8-\mathrm{H} 3{ }^{\prime}$ were found in the 2D NOESY (Fig. 2). We therefore calculated two sets of structures for each molecule having G72 constrained either in a syn or in an anti conformation (see Materials and Methods, Structure calculation). Superimposition of all heavy atoms in the most rigid part of apoB mRNA (G54A67, A73-A76, A79-C84) results in average pairwise root mean squared deviations (rmsd) between $1.6 \AA$ and $1.9 \AA$ for the four ensembles of structures (Table 1; Fig. 3A). The remaining nucleotides A68-G72, G77, and U78 are relatively disordered in all four ensembles. Interestingly, C66 and U66 are structured with their bases stacked between the bases of A65 and A67 (Fig. 3B). Also, quite surprisingly, $4 \mathrm{nt}$ (U71, G72, G77, and U78) of the $11 \mathrm{nt}$ of the mooring sequence are unstructured. This flexibility may play a central role in the RNA recognition by the editing factors. 
TABLE 1. Structure determination statistics

\begin{tabular}{|c|c|c|c|c|}
\hline & & mRNA unedited & & ApoB mRNA edited \\
\hline \multicolumn{5}{|l|}{ Number of experimental restraints } \\
\hline Distance restraints from NOEs & \multicolumn{2}{|r|}{469} & & 466 \\
\hline \multicolumn{5}{|l|}{ Within the stem } \\
\hline Intranucleotide & \multicolumn{2}{|r|}{185} & & 185 \\
\hline Internucleotide & \multicolumn{2}{|r|}{170} & & 170 \\
\hline Long-range & \multicolumn{2}{|r|}{21} & & 21 \\
\hline Number of NOEs per residue & \multicolumn{2}{|r|}{16} & & 16 \\
\hline \multicolumn{5}{|l|}{ Within the loop without G72 } \\
\hline Intranucleotide & \multicolumn{2}{|r|}{51} & & 53 \\
\hline Internucleotide & \multicolumn{2}{|r|}{40} & & 35 \\
\hline Long-range & \multicolumn{2}{|r|}{2} & & 2 \\
\hline Number of NOEs per residue & \multicolumn{2}{|r|}{13} & & 12 \\
\hline Number of $\delta$ dihedral angles & \multicolumn{2}{|r|}{31} & & 31 \\
\hline Number of $\mathrm{H}$-bond restraints (two per bond) & \multicolumn{2}{|r|}{20} & & 20 \\
\hline Total number of experimental restraints & \multicolumn{2}{|r|}{520} & & 517 \\
\hline \multicolumn{5}{|l|}{ Structure calculation statistics } \\
\hline Base conformation & Syn & Anti & Syn & Anti \\
\hline Number of refined structures & 20 & 20 & 16 & 20 \\
\hline Number of distance violations $<0.3 \AA^{a}$ & 1 & 2 & 2 & 1 \\
\hline Number of angle violation $5^{\circ}<$ & 0 & 0 & 0 & 0 \\
\hline \multicolumn{5}{|l|}{ Deviations from idealized covalent geometry } \\
\hline Bonds $(\AA)$ & $9 \pm 2 \times 10^{-3}$ & $9 \pm 3 \times 10^{-3}$ & $9 \pm 2 \times 10^{-3}$ & $9 \pm 2 \times 10^{-3}$ \\
\hline Angles (degree) & $2.4 \pm 0.2$ & $2.4 \pm 0.2$ & $2.3 \pm 0.2$ & $2.3 \pm 0.2$ \\
\hline \multicolumn{5}{|l|}{ Pairwise rmsd for heavy atoms $(\AA)$} \\
\hline Stem-loop (G54-A67, A73-A76, A79-C84) & $1.9 \pm 0.7$ & $1.8 \pm 0.6$ & $1.6 \pm 0.5$ & $1.6 \pm 0.4$ \\
\hline Lower stem (G54-U59, A79-C84) & $0.5 \pm 0.2$ & $0.5 \pm 0.2$ & $0.6 \pm 0.4$ & $0.4 \pm 0.1$ \\
\hline Upper stem (U61-U64, A73-A76) & $1.0 \pm 0.2$ & $0.9 \pm 0.2$ & $0.9 \pm 0.2$ & $0.9 \pm 0.2$ \\
\hline Loop (A65-A67) & $1.1 \pm 0.4$ & $1.2 \pm 0.5$ & $0.9 \pm 0.5$ & $1.1 \pm 0.4$ \\
\hline
\end{tabular}

Structure of the editing site before (C66) and after editing (U66)

For both RNAs, at the $5^{\prime}$ side of the loop, residues A65, the editing site C66 (or U66), and A67 are clearly stacked in all structures (within $1 \AA$ rmsd) (Table 1; Fig. 3B). Several sequential sugar to aromatic and aromatic to aromatic NOE cross-peaks of moderate to strong intensity from U64 to A68 were found supporting this short helical stacking at the 5 ' side of the octa-loop. Comparison of the proton chemical shifts between the edited (U66) and unedited (C66) apoB mRNA shows only a few differences, suggesting that editing does not create a major structural rearrangement of the free RNA (Fig. 2). This structural feature, namely, a helical stacking at the $5^{\prime}$ end of the RNA loop was already observed in several other RNA stem-loop structures (Bouvet et al. 2001).

Beside stacking, C66 and U66 are further stabilized by interacting with either G72 or U71 as found in the majority of the calculated conformers. In the unedited RNA, we found some conformers where C66 forms a base pair with G72 when G72 is in the anti conformation (Fig. 4A). This GC base pair results from a few sequential NOEs. Unfortunately, we could not prove unambiguously this interac- tion since we could not observe G72 imino proton due to the syn-anti conformational exchange of G72. Similarly, when G72 is in the syn conformation, one amino proton of C66 can be hydrogen-bonded with either G72 (N7; Fig. 4B) or U71 (O4; not shown). In the edited apoB mRNA (U66), an additional imino proton with a broad line is present at 11.19 ppm that we assigned to U66 (Fig. 5A). U66 imino has very weak NOE cross-peaks, suggesting that U66 imino might be weakly hydrogen-bonded, but the NMR data were too ambiguous to precisely identify the hydrogen-bond acceptor. These NOEs could be assigned to A65 and A67 protons but were not introduced in the structure calculation as a restraint (data not shown). In agreement with this, we found in several of the calculated conformers U66 imino hydrogen-bonded with G72 O6 when G72 is in the anti conformation (Fig. 4C) and with G72 N7 when G72 is in the syn conformation (Fig. 4D).

\section{Structure of the spacer element A67-A68-U69-U70}

As discussed above, A67 is found stacked over the editing site (C66 or U66) and A68 over A67 in most of the struc- 

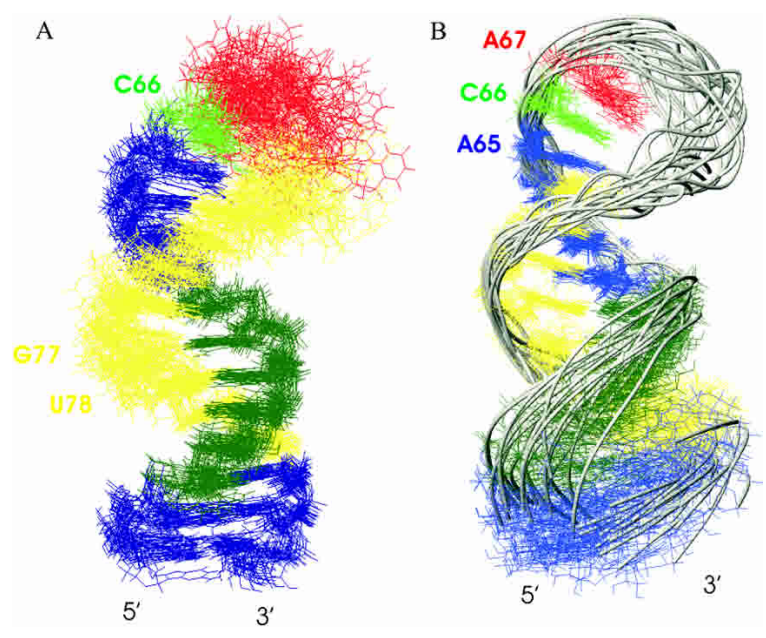

FIGURE 3. (A) Superposition of the 20 lowest energy structures of the unedited apoB mRNA (G72 syn conformation) (the structures are superimposed on G54-A67, A73-A76, and A79-C84). The colors refer to the different elements of the apoB mRNA secondary structure described in Figure 1. (B) Stacking of C66 editing site between two adenines of the unedited apoB mRNA (G72 syn conformation). The C66 edited cytidine is light green, the upper adenine A67 is red, and the lower adenine is blue (the 20 lowest energy structures are superimposed on U61-A67, A73-A76).

tures (there are several sequential NOEs between A67 and A68). U69 and U70 are mostly disordered in the structures because of the limited number of medium strong NOEs present in the NOESY spectra of both RNAs. This also reflects the genuine flexibility of these nucleotides as indicated by much sharper lines for their aromatic resonances
A

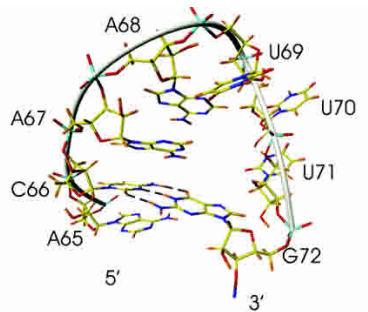

C

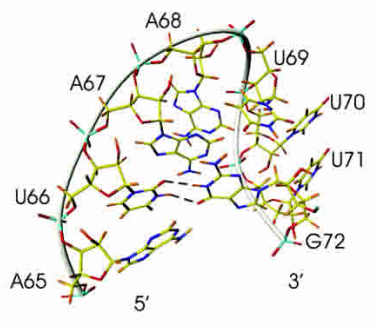

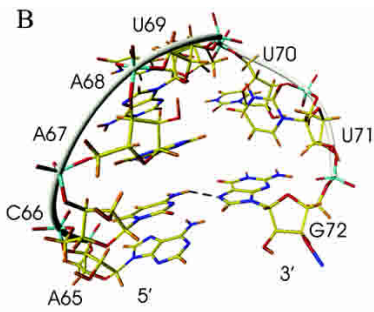

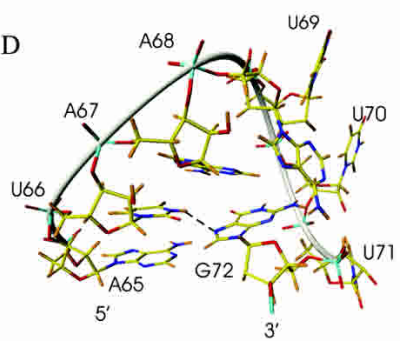

FIGURE 4. Potential interactions involving C66 amino group and U66 imino proton are shown in representative conformers of both the unedited and the edited apoB mRNAs. (A) C66 forms a base pair with G72 anti. (B) With G72 syn, C66 amino interacts with G72 N7. (C) U66 forms a base pair with G72 anti (D) U66 imino can interact with G72 ${ }_{s y n}$ N7.
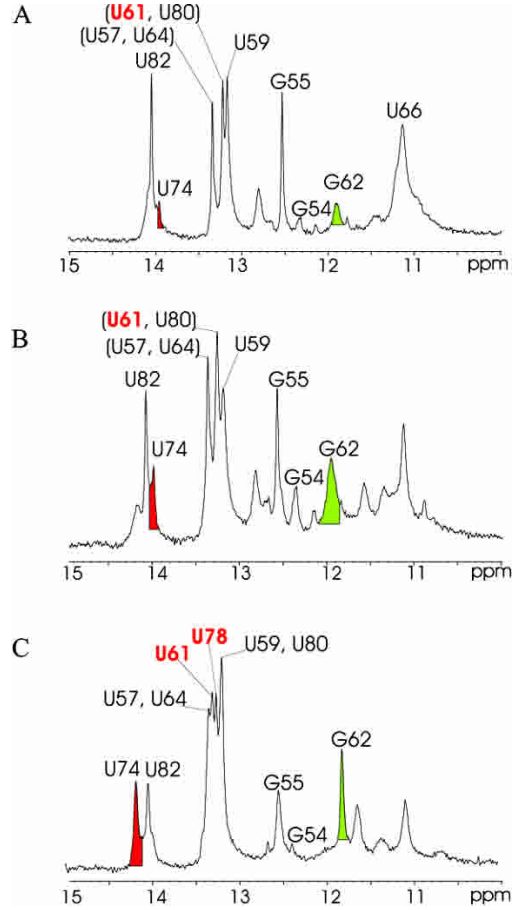

FIGURE 5. The $1 \mathrm{D}$ imino proton spectra in $\mathrm{H}_{2} \mathrm{O}:(A)$ apoB mRNA edited (U66), $(B)$ apoB mRNA unedited (C66), and $(C)$ apoB mRNA without G77. Some additional imino protons are due to the presence of the $n+1$ and $n-1$ RNA forms from the T7 transcription synthesis.

(H5 and H6) (U69 shown in Fig. 2A) than the other pyrimidines and by a $\mathrm{H1}^{\prime}-\mathrm{H}^{\prime}{ }^{3} \mathrm{~J}$ coupling between 6 and $7 \mathrm{~Hz}$ indicative of a sugar pucker in exchange between $\mathrm{C}^{\prime}$ and C2' endo conformations (Fig. 6).

Structure of the mooring sequence U71-A81 and the efficiency sequence within the stem-loop

U71 is disordered and has the same spectroscopic behavior as U69 and U70 (described above). G72 base in both RNAs is clearly exchanging between syn and anti conformations. This exchange is indicated spectroscopically by intense NOE cross-peaks between G72 H8 and both its own $\mathrm{H1}^{\prime}$ (indicative of a syn conformation) and its own $\mathrm{H}^{\prime}$ (indicative of an anti conformation) (Fig. 2). Figure 4 shows a representative structure of the loop around G72 for each of the four ensembles of structures. A few NOEs support these four different loop conformations (see Materials and Methods).

The remaining residues of the mooring sequence (A73A81) together with U57-U64 form an irregular A-form helix interrupted by a 3-nt internal loop composed of G77, U78, and A60 that belongs to the efficiency sequence. The G77-A60-U78 nucleotides form a flexible internal loop since A60 is not clearly involved in base pairing with U78 or G77 (Fig. 7). Indicative of this flexibility, U78 sugar pucker is found in exchange between $C 2^{\prime}$ and $C 3^{\prime}$ endo conformations as indicated by a ${ }^{3} \mathrm{~J}_{\mathrm{H}^{\prime}-\mathrm{H} 2^{\prime}}$ coupling constant of $6 \mathrm{~Hz}$ (Fig. 6) although the other 2 nt adopt a $C 3^{\prime}$ endo confor- 

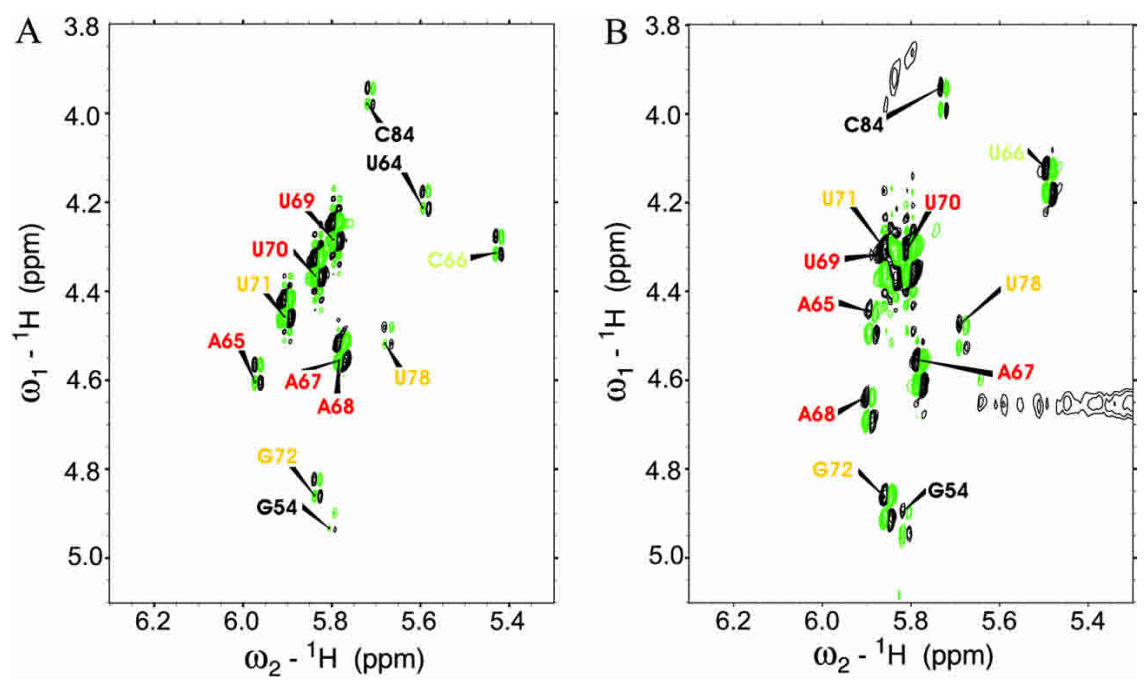

Implication for $C$ to $U$ editing of the two apoB mRNA stem-loop solution structures

In all mammalian species where apoB mRNAs are efficiently in vitro edited with rabbit liver $\$ 100$ extract, the octaloop and the mooring sequence are highly conserved, showing the importance of these cis-acting elements in the editing specificity (Hersberger et al. 1999). Here, we find that the editing site (C66) is sandwiched between two adenosines (A65 and A67), C66 amino group pointing inside the loop. The structure therefore suggests that a conformational change of the loop must take place during the editing reaction of deamination in order to expose the amino group of C66 to APOBEC1. This structural finding gives a rational explanation for why APOBEC1 alone

FIGURE 6. DQF-COSY spectra of the unedited $(A)$ and edited $(B)$ ApoB mRNA in the region of the $\mathrm{H}_{1}^{\prime}\left(\mathrm{W}_{2}\right.$ axis)- $\mathrm{H}_{2}^{\prime}\left(\mathrm{W}_{1}\right.$ axis) correlations. The positive and negative contours are black and green, respectively. The numbering color is done according to the different cis-acting elements. Signals from the stem resonances were not detected except from G54, U64, and U78.

mation. A few conformers show a G77-A60 base pair but since G77 imino could not be observed, we could not prove it unambiguously. The presence of this internal loop increases the flexibility of the two surrounding A-U base pairs (A76-U61 and A79-U59). Weak cross-peaks between the adenine $\mathrm{H} 2$ proton and the uracil $\mathrm{H} 3$ imino protons support the dynamical aspect of these A76-U61 and A79-U59 base pairs. Also, the other three base pairs (U64-A73, A63U74, and G62-C75) between the octa-loop and the internal loop are not perfectly rigid, as indicated by the broad lines of G62 and U74 imino proton resonances (Fig. 5A,B). Interestingly, the imino proton lines of G62 and U74 become much sharper when the internal loop is removed (when G77 is deleted) (Fig. 5C). This observation confirms the hydrogen bond weakness of the upper stem base pairs when the internal loop is present. Also, U64 sugar pucker like U78 is in exchange between the $C 2^{\prime}$ and $C 3^{\prime}$ endo conformation (Fig. 6). Trans-hydrogen bond scalar couplings of most of the lower stem base pairs (from G55-C83 to U59-A79) and only one base pair of the upper stem (A63-U74) could be detected and clearly identified with an HNN-COSY experiment (Dingley and Grzesiek 1998; data not shown). These data show first the rigidity of the lower stem that includes the efficiency sequence and the $3^{\prime}$ end of the mooring sequence and, second, some flexibility of the upper stem. The rigid aspect of the lower stem results from the two additional G-C base pairs that substitute the internal loop present in the wild-type secondary structure.

In summary, almost the entire mooring sequence is found to be from very dynamic (U71, G72) to moderately dynamic (A73-A79). Only U80 and A81 of the mooring sequence and the efficiency sequence are rigid in our structures because of the two additional G-C base pairs that are present in our construct. cannot deaminate $\mathrm{C} 66$ efficiently at $28^{\circ} \mathrm{C}$ but can from $42^{\circ} \mathrm{C}$ to $60^{\circ} \mathrm{C}$ (Chester et al. 2004). From $42^{\circ} \mathrm{C}$, the stem-loop starts melting (see section ApoB mRNA recognition by ACF and APOBEC1) and is fully denatured at $55^{\circ} \mathrm{C}$ (NMR data shown). The base of cytidine C66 is therefore fully exposed to the solvent.

Most of the highly conserved spacer nucleotides (A67, A68, U69, and U70) are flexible. Since the spacer composition can be modified without totally abolishing the editing reaction (nucleotide addition and substitution), the type of nucleotide does not seem to be critical as long as the loop flexibility is maintained (Backus and Smith 1992; Driscoll et

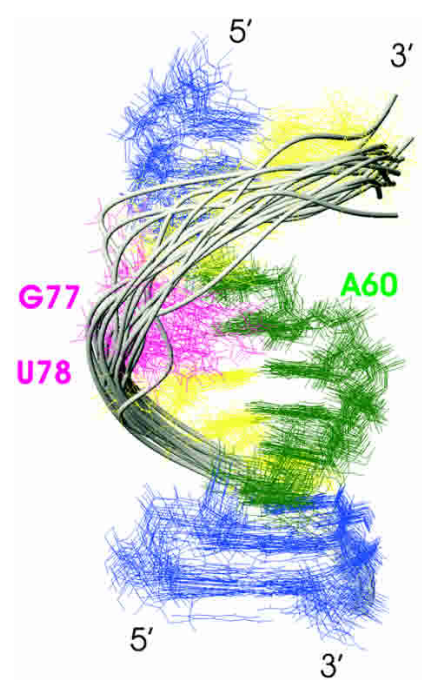

FIGURE 7. Flexibility of the G77-A60-U78 internal loop of the unedited apoB mRNA (G72 syn conformation) (the 20 lowest energy structures are superimposed on G54-U64, A73-A76, A79-C84). U78 and G77 nucleotides are colored in red. 
al. 1993). Adding up to eight new nucleotides (AU motif) in the spacer or moving the editing site $3 \mathrm{nt}$ upstream between two Watson-Crick base pairs does not prevent the editing from occurring, but substantially reduces the reaction yield. The spacer plays two roles: It maintains the right distance between the editing site and the mooring sequence and it guarantees the flexibility of the loop and of part of the mooring sequence.

From our structures of the human apoB mRNA, it appears that the partially unstructured octa-loop and the presence of an internal loop confer flexibility to the mooring sequence. This flexibility might play a critical role in the process of RNA recognition by the editing factors. Almost half of the mooring sequence is located within the loop and the internal loop. In particular, the unpaired nucleotides U71, G72, G77, and U78 (found here flexible) could serve as a primary recognition site for ACF and contribute to denature the stem in order to expose the full mooring sequence for protein binding. Indeed, although ACF binds with high affinity (apparent $K_{d}$ of $8.0 \pm 4 \mathrm{nM}$ ) to a 280 -nt apoB mRNA, ACF does not bind the same sequence when annealed to its antisense strand (Mehta and Driscoll 2002). This suggests that ACF does not recognize the mooring sequence within a regular A-form helix but rather in the context of a flexible stem containing bulge and/or internal loop. G77 within the internal loop might not be recognized specifically by ACF since its substitution does not affect the editing yield. However, G77 contributes to the mooring sequence recognition by disrupting the helix regularity. It is interesting to note that in all known species, the mooring sequence of the apoB-mRNA is always embedded in an irregular stem-loop containing bulges or an internal loop (Fig. 8A). This common feature suggests that such a dynamic environment is essential for the mooring sequence recognition and a specific editing at position C66. The iden-

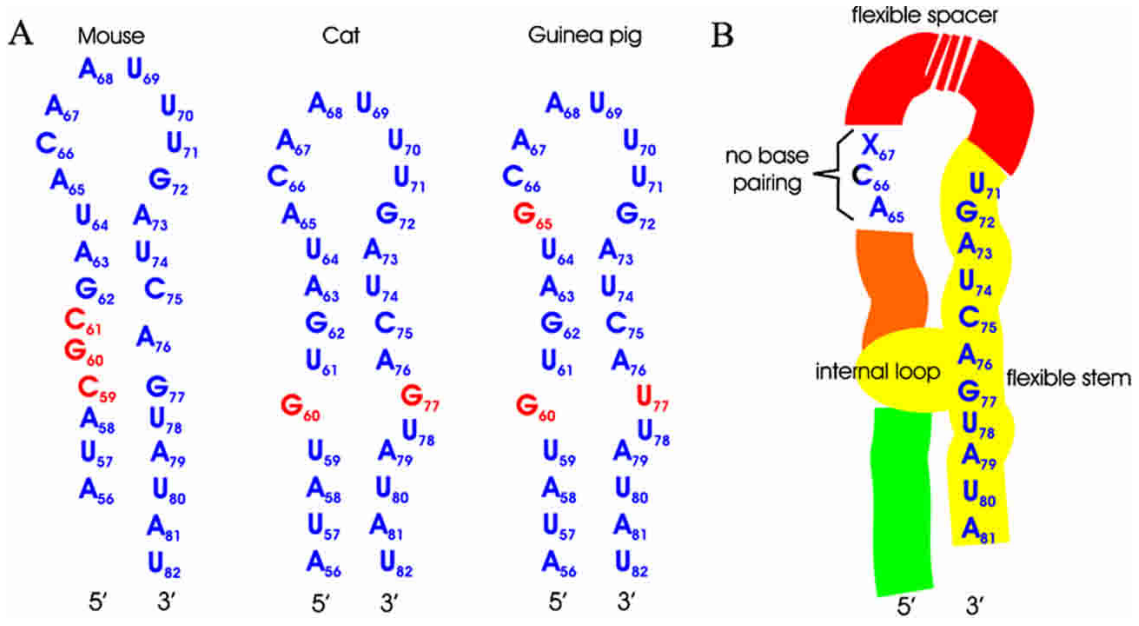

FIGURE 8. (A) Sequences and different predicted secondary structures of mammalian apoB mRNAs (nucleotides that are different from the human sequence are indicated in red). $(B)$ Characteristic elements of the mammalian apoB mRNA stem-loop. X can be any nucleotide. tities of the nucleotides surrounding the editing site are critical because they can prevent the cytosine accessibility to the active site of the enzyme by base pairing or by making unfavorable interactions with the proteins during the editing reaction. This might explain why a guanosine instead of the adenosine A65 in the guinea pig apoB-mRNA (Fig. 8A) leads to the RNA being poorly edited by the rabbit liver S100 extract. Based on the present structure of the human ApoB-mRNA and the different apoB mRNA stem-loops found in mammalians, it seems that efficient $\mathrm{C}$ to $\mathrm{U}$ editing of ApoB-mRNA requires a flexible mooring sequence containing a bulge or an internal loop, a flexible spacer, and no strong base pairing of the editing site with the surrounding nucleotides (Fig. 8B).

\section{ApoB mRNA recognition by ACF and APOBEC1}

We have studied the $\mathrm{N}$-terminal part of ACF containing only the three RRMs (ACF34) important to specifically recognize RNA (Fig. 9A; Blanc et al. 2001a; Mehta and Driscoll 2002). The ACF region interacting with both apoB mRNA and APOBEC1 includes the three RRMs and an RG-rich domain (Fig. 9A). We have investigated by NMR the apoB mRNA substrate in complex with ACF34 to understand how ACF34 recognizes the stem-loop. This NMR study is complemented by biochemical experiments in order to localize the sites of apoB mRNA binding to ACF and APOBEC1.

ACF34 binds and denatures the ApoB-mRNA stem-loop at physiological temperature

RNA binding studies were performed with ACF34 containing an N-terminal hexahistidine tag in complex with the 31-nt stem-loop (SL31) at low salt concentration (20 mM $\mathrm{NaCl}$ ) and different temperatures (see Materials and Methods). Two-dimensional $\left({ }^{1} \mathrm{H}_{-}{ }^{15} \mathrm{~N}\right)$ HSQC and $\left({ }^{1} \mathrm{H}_{-}{ }^{1} \mathrm{H}\right)$ TOCSY were recorded to monitor the resonance changes in the protein and in the RNA, respectively, from $30^{\circ} \mathrm{C}$ to $42^{\circ} \mathrm{C}$, a temperature range in which the complex is still stable. Figure $9 \mathrm{~B}$ shows the $\left({ }^{1} \mathrm{H}_{-}{ }^{15} \mathrm{~N}\right) \mathrm{HSQC}$ of the free ACF34 protein at $25^{\circ} \mathrm{C}$. ACF34 is only stable at high salt concentration and starts precipitating significantly over $30^{\circ} \mathrm{C}$. In complex with apoB mRNA SL31 (ratio 1 to 1), ACF34 did not give a good $\left({ }^{1} \mathrm{H}-{ }^{15} \mathrm{~N}\right)$ HSQC spectrum quality at high salt concentration. After dialysis in low salt buffer $(20 \mathrm{mM}$ $\mathrm{NaCl}$ ) and concentration of the complex, the linewith of the protein peaks improved significantly. At $25^{\circ} \mathrm{C}$, 
A

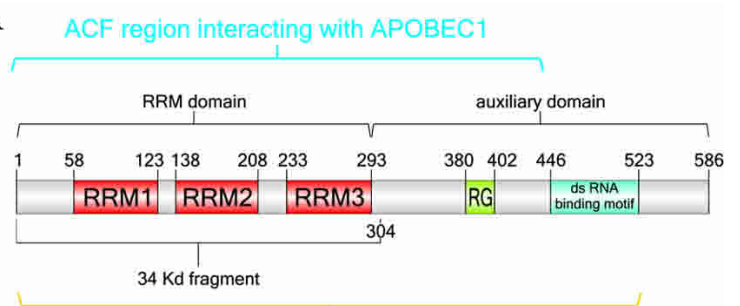

ACF region interacting with ApoB mRNA

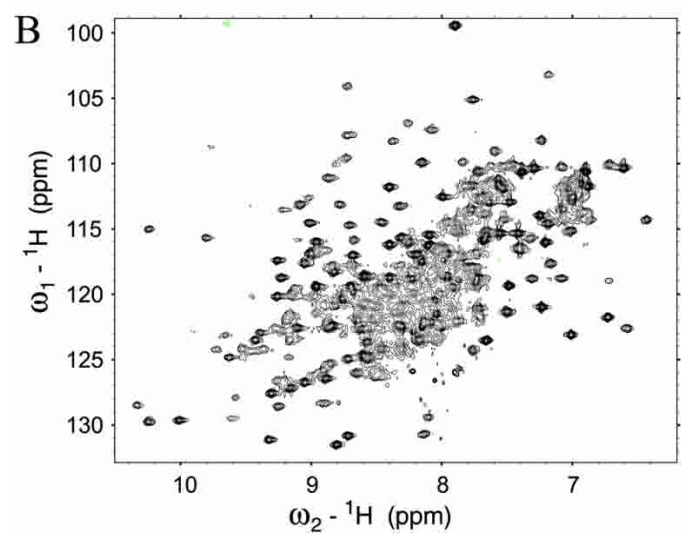

FIGURE 9. (A) ACF domain structure and ACF region interacting with APOBEC1 and apoB mRNA (Blanc et al. 2001a; Mehta and Driscoll 2002). (B) $\left({ }^{1} \mathrm{H}^{15} \mathrm{~N}\right)$ HSQC spectrum of $1 \mathrm{mM}\left({ }^{1} \mathrm{H}^{15} \mathrm{~N}\right)$ labeled ACF34 protein in $30 \mathrm{mM}$ sodium phosphate, $170 \mathrm{mM} \mathrm{NaCl}$ (pH 8.0), acquired at $900 \mathrm{MHz}$ and $25^{\circ} \mathrm{C}$.

ACF34 appears to bind weakly the RNA without denaturing the secondary structure as indicated in Figure 10. Among the pyrimidines, C66, U71, and U78 show the largest chemical shift perturbations upon protein binding. Interestingly, U71 and U78 belong to the mooring sequence and are both found flexible in the free RNA structure that we have determined. This flexibility might play a precursor role in the recognition of the RNA by the protein. The chemical shift change observed also for $\mathrm{C} 66$ might be due to a structural change of U71. The $\left({ }^{1} \mathrm{H}-{ }^{15} \mathrm{~N}\right)$ HSQC spectrum of the protein under those conditions shows very broad lines, indicating multiple conformations and probably a weak interaction between ACF and SL31 (data not shown).

At $37^{\circ} \mathrm{C}$, the protein resonance line in the $\left({ }^{1} \mathrm{H}^{-}{ }^{15} \mathrm{~N}\right)$ HSQC spectrum sharpened (data not shown) and at the same time the H5-H6 TOCSY cross-peaks from the RNA stem disappeared almost completely (Fig. 11, 2B). At this temperature, in a $1 \mathrm{D}{ }^{1} \mathrm{H}$ spectrum of the complex, all RNA imino peaks indicative of the RNA secondary structure disappeared while they were present at $25^{\circ} \mathrm{C}$ (not shown). It should be noticed that at $37^{\circ} \mathrm{C}$, the free SL31 stem-loop was intact (Fig. 11, 1B) and totally denatured only at $55^{\circ} \mathrm{C}$ (data not shown). When the temperature of the SL31-ACF34 complex was raised to $42^{\circ} \mathrm{C}$, all the $\mathrm{H} 5-\mathrm{H} 6$ cross-peaks indicative of an RNA stem (indicated by green circles in Fig. 11, 2C) disappeared from the $\left({ }^{1} \mathrm{H}-{ }^{1} \mathrm{H}\right)$ TOCSY spectrum, indicating that ACF34 binds SL31 as a single strand (Fig. 11, 2C). We could not monitor the melting of the stem-loop in complex with ACF34 by UV spectroscopy because of the free protein precipitation above $30^{\circ} \mathrm{C}$, rendering a proper melting temperature measurement impossible. This study clearly shows that ACF34 can bind effectively apoB-mRNA SL31 and more importantly can totally melt the stem-loop structure. As shown in our structure of the free SL31, C66 is sandwiched between two adenosines and its amino group is not easily accessible. Thus, by melting the RNA stemloop, we postulate that ACF34 disrupts the structure around C66 making the cytosine accessible for deamination by APOBEC1.

RNA binding by ACF confers specificity for apoB mRNA editing by $A P O B E C 1$

To investigate the role of ACF in inferring specificity for apoB mRNA editing, we performed in vitro assays with purified recombinant APOBEC1 and ACF at $30^{\circ} \mathrm{C}$. Substrates used in this study include human wild-type 55-nt apoB mRNA (6649-6703) and its mutants (Mut B-F) as previously described (Fig. 12A; Shah et al. 1991; see also Materials and Methods section). Purified APOBEC1 alone displayed a low level of editing activity on wild-type $55 \mathrm{mer}$ RNA. Mooring sequence mutants Mut D and Mut E were edited at a higher level compared to Mut B, Mut C, and Mut F (Fig. 12A). We previously reported that a partially purified editing complex only edited wild-type and RNA mutants Mut B, Mut $\mathrm{C}$, and Mut $\mathrm{F}$ with an intact mooring sequence. The editing observed with Mut D and Mut E by

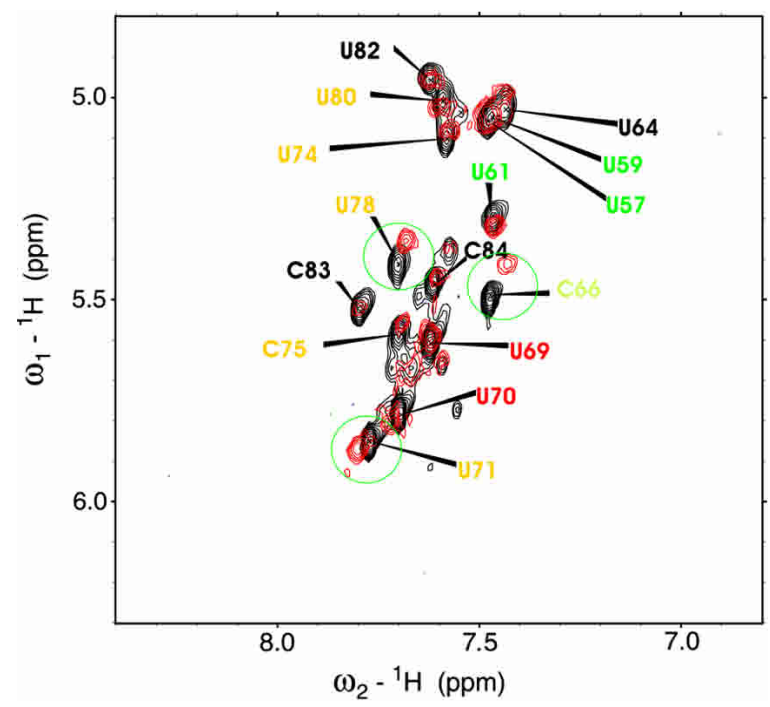

FIGURE 10. Overlay of the $\left({ }^{1} \mathrm{H}^{1} \mathrm{H}\right)$ TOCSY spectra of $\mathrm{H} 5-\mathrm{H} 6$ pyrimidine correlations of free SL31-apoB mRNA (black contours) and in complex with ACF34 (red contours) $(0.5 \mathrm{mM}$ complex concentration) acquired at $25^{\circ} \mathrm{C}$ in low salt $(20 \mathrm{mM} \mathrm{NaCl})$ phosphate buffer $(\mathrm{pH}$ 8.0 ). The circles indicate the chemical shift changes of C66, U71, and U78. 
$1 \mathrm{~A}$

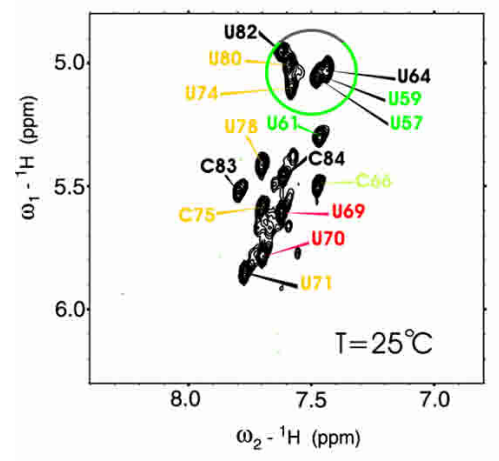

$2 \mathrm{~A}$

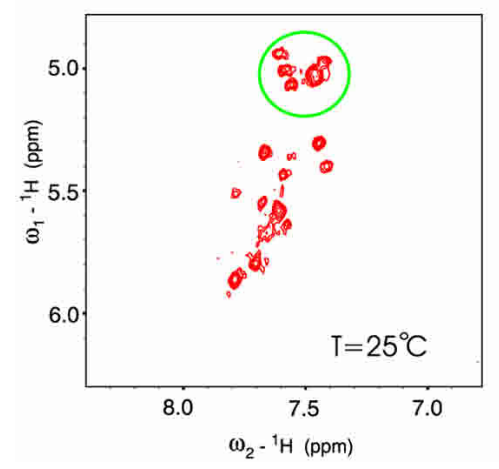

1B

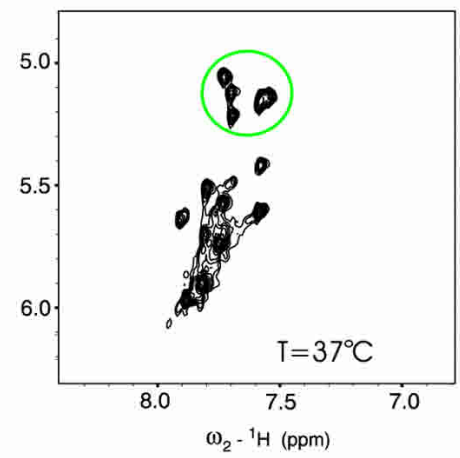

2B

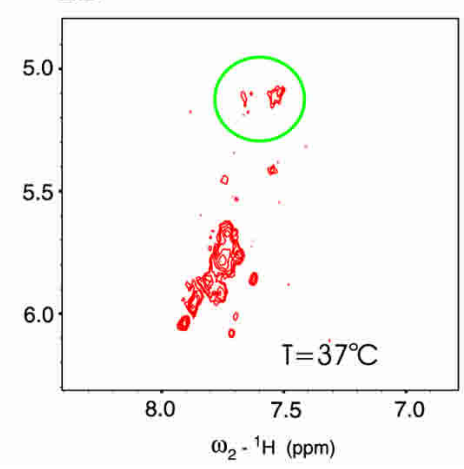

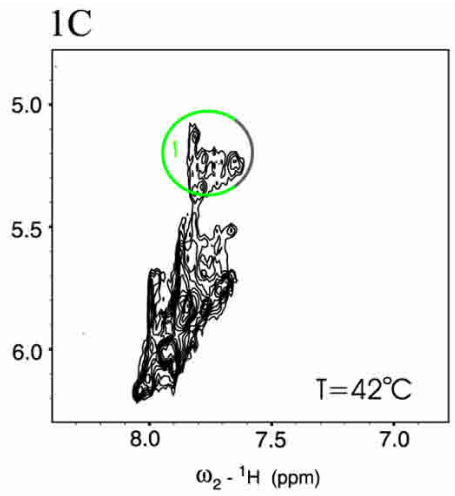

$2 \mathrm{C}$

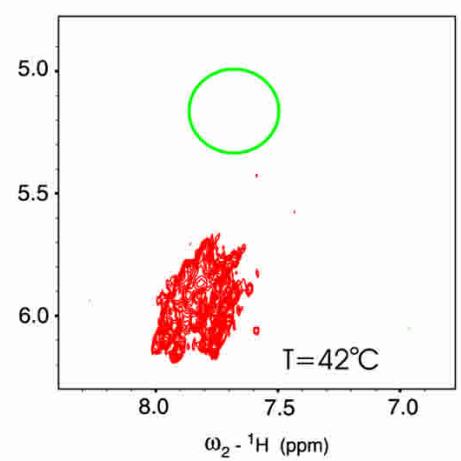

FIGURE 11. Melting of the apoB mRNA SL31 without (1A, 1B, and $1 \mathrm{C})$ and with $(2 \mathrm{~A}, 2 \mathrm{~B}$, and $2 \mathrm{C}) \mathrm{ACF} 34$ in low salt buffer $(20 \mathrm{mM} \mathrm{NaCl})$ monitored by series of $\left({ }^{1} \mathrm{H}^{-1} \mathrm{H}\right)$ TOCSY at different temperatures. The green circles indicate the location of the $\mathrm{H} 5-\mathrm{H} 6$ correlations of uracils in the stem.

APOBEC1 alone resembles "hyperediting," as it is neither ACF- nor mooring-sequence-dependent and presumably nonspecific.

Addition of ACF reduced Mut D and Mut E editing and increased editing of other substrates compared to the same experiments with APOBEC1 alone (Fig. 12A). Increasing amounts of ACF completely prevented the editing of Mut D and Mut E by APOBEC1 (data not shown). ACF del 55, a splice variant of ACF lacking the RRMs, neither bound nor complemented editing (data not shown). These results suggest that ACF binding to the mooring sequence and its interaction with APOBEC1 is important to confer site-specific editing.

APOBEC1 binds to AU-rich regions in apoB mRNA (Anant et al. 1995; Navaratnam et al. 1995). To nonspecifically edit apoB mRNA, APOBEC1 must be able to bind RNA at multiple sites. To precisely map the site of APOBEC1 and ACF interaction on apoB mRNA, we generated sitespecifically labeled apoB mRNA by RNA ligation (Moore and Sharp 1992). A ${ }^{32} \mathrm{P}$ label was introduced at the $5^{\prime}$ end of positions C6666 and U6674, which are essential for editing (Navaratnam et al. 1993) and its complement A6663 along with A6681 (Fig. 12B). We also generated a sitespecific labeled U6674 of Mut E (E6674). These substrates with identical specific activity were used in UV cross-linking experiments carried out at $30^{\circ} \mathrm{C}$ with $\mathrm{APOBEC} 1$ and/or
ACF. APOBEC1 exhibited strong cross-linking at position 6681 and weaker cross-linking at other sites $(6663,6666$, and 6674) whereas ACF cross-linked strongly at position 6674 and moderately at position 6663. ACF and APOBEC1 both failed to bind Mut E at position 6674 (E6674 in Fig. 12C).

To further examine the binding of APOBEC1 and ACF to the RNA, APOBEC1 and ACF mixed at various molar ratios were cross-linked as before. When the ACF to APOBEC1 ratio was $>2$, sites of ACF binding to the RNA remained the same whereas APOBEC1 binding was limited to 6681. When the ratio was reversed, APOBEC1 binding was stronger at position 6681 and weak binding was found at other sites as before. ACF binding remained the same (Fig. 12D). These results suggest that APOBEC1 alone can bind multiple sites on the RNA and can edit cytidines nonspecifically as observed in hyperediting (Fig. 12A; Yamanaka et al. 1996). Strong ACF binding at position 6674 and moderate binding at site 6663 suggest that ACF binds the RNA asymmetrically across the previously identified stem (Richardson et al. 1998) and prefers the region containing the mooring sequence. Lack of ACF binding to Mut E (E6674) confirms that ACF binds preferentially to this site/region on the RNA (Fig. 12D). ACF has a greater binding affinity than APOBEC1 since varying the molar ratios of APOBEC1 to ACF does not affect the ACF binding sites on the RNA. The ACF inability 

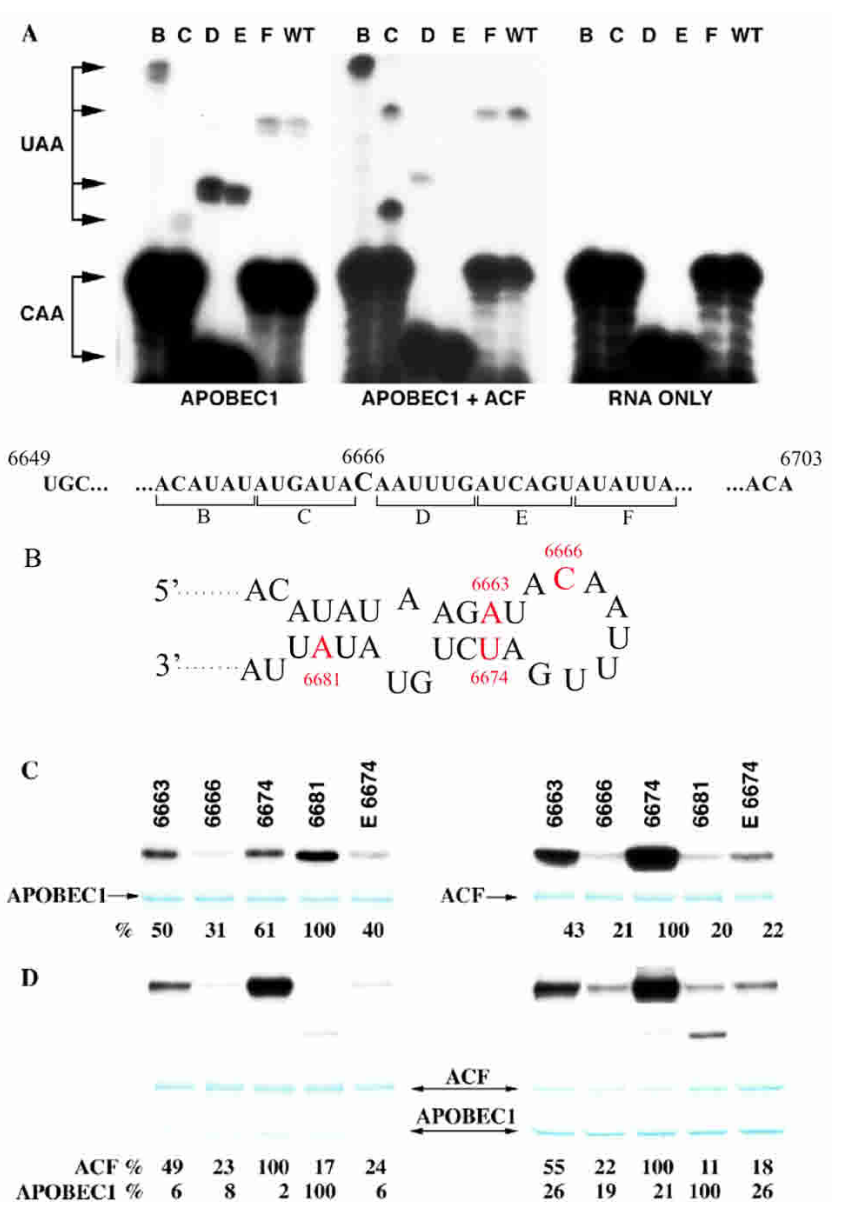

FIGURE 12. ACF specifies site-specific RNA binding and editing by APOBEC1. (A) Editing (UAA) of apoB mRNA mutants (B, C, $\mathrm{D}, \mathrm{E}$, and F) and wild type (WT) by APOBEC1 (left), APOBEC1 and ACF (middle), and RNA control (right) are shown. (CAA) The unedited site. $(B)$ Site-specific labeled sites (red) shown on the stem-loop structure of the 55-nt apoB mRNA. (C) UV cross-linking of RNA labeled $5^{\prime}$ of positions $6663,6666,6674,6681$, and Mut E 6674 with APOBEC1 $(0.5 \mathrm{mg})$ (left) and ACF $(0.5 \mathrm{mg})$ (right). RNA binding is shown as a percentage of the best binding. Coomassie stained proteins are shown. (D) UV cross-linking of labeled RNAs as in $C$ with ACF:APOBEC1 ratio > 2:1 (left) and APOBEC1:ACF ratio > 2:1 (right). Coomassie stained proteins are shown and the level of RNA binding is shown as a percentage of the best binding for ACF or APOBEC1.

to bind Mut D (E6674) RNA also suggests that binding is sequence specific. Higher concentrations of ACF appear to limit APOBEC1 binding to a single site (6681). This concentration effect suggests that ACF, in addition to specifically binding to the RNA, restricts access of APOBEC1 to a single site (C6666) for editing.

\section{Proposed mechanism of ApoB mRNA C to U editing}

Together with our NMR studies, these biochemical data lead us to propose a new model on how ACF specifies the site of $\mathrm{C}$ to $\mathrm{U}$ editing in ApoB-mRNA (Fig. 13). ACF not only recognizes specifically the mooring sequence but also triggers a conformational change of the editing site (C6666). Our NMR results of the complex at $25^{\circ} \mathrm{C}$ (Fig. 10) suggest a plausible intermediate step where ACF contacts the flexible nucleotides of the mooring sequence with the ApoB-mRNA stem-loop still folded (located in the loop and internal loop). Subsequently, ACF will melt the RNA stem-loop as shown by our NMR data of the complex at higher temperature (Fig. 11), ACF contacting both the mooring sequence and its opposite strand as shown from site-specific UV cross-linking (Fig. 12). The resulting conformational change exposes the amino group of the target cytidine, not accessible in the free form, to the enzymatic site of APOBEC1, as shown schematically in Figure 13. We postulate that after dissociation of the ACF-APOBEC1 complex, ApoB-mRNA stem-loop will refold like the nonedited one since the edited RNA adopts the same structure (Fig. 4). These findings are reminiscent of the gene regulation mechanism in bacteria where temperature triggers gene expression by melting RNA stem-loops (Chowdhury et al. 2003). Here, it is not the temperature but rather ACF that triggers the RNA melting, allowing the editing reaction to take place.

\section{MATERIALS AND METHODS}

\section{RNA preparation}

Three different sequences of RNA were prepared: the 31-nt apoB mRNA 5'-GGAUAUAUGAUACAAUUUGAUCAGUAUAUCC $3^{\prime}$, the apoB mRNA edited (U66), and the apoB mRNA without G77 nucleotide. All three RNAs were synthesized enzymatically from synthetic single-stranded DNA templates (48 nt for apoB mRNA) using E. coli His $_{6}$-tagged T7 RNA polymerase (Price et al. 1998). RNA was purified by denaturing $16 \%$ polyacrylamide gel electrophoresis, identified by UV absorbance, and excised from the gel. RNA was recovered by electro-elution, ethanol precipitated, purified on an $8 \mathrm{~mL}$ DEAE anion exchange column, again ethanol precipitated, and desalted on a 120 -mL G-15 gel filtration column. The yields of three different unlabeled RNA preparations were $~ 0.4-0.5 \mathrm{mg}$ of RNA per milliliter of total transcription volume. Before lyophilizing, the purified samples (10-15 mL) were heated at $75^{\circ} \mathrm{C}$ for $3 \mathrm{~min}$ and cooled immediately in liquid nitrogen for $5 \mathrm{~min}$. This temperature shock leads preferentially to the formation of the monomer (Zanier et al. 2002). Then, they were dissolved in $500 \mu \mathrm{L}$ of $40 \mathrm{mM} \mathrm{NaH} \mathrm{PO}_{4}$ buffer at $\mathrm{pH}$ 5.8. They were lyophilized and dissolved either in $99.99 \% \mathrm{D}_{2} \mathrm{O}$ or $10 \%$ $\mathrm{D}_{2} \mathrm{O}+90 \% \mathrm{H}_{2} \mathrm{O}$. The final concentrations of unlabeled RNA were $2.0 \mathrm{mM}$. Some impurities from the RNAs having $n-1$ or $n+1 \mathrm{nt}$ were also present at low concentration $(>1 \%)$ in the sample since we could not separate these RNA bands from the main RNA band on the purification gel.

Different ${ }^{13} \mathrm{C}$ and ${ }^{15} \mathrm{~N}$ labeled samples were prepared for assignment. The labeled RNAs were prepared with Ampliscribe T7 Polymerase purchased at Epicentre since the yields were multiplied by a factor of 2 or 3 compared to those of our homemade $\mathrm{His}_{6}$-tagged T7 polymerase $(1.0-1.5 \mathrm{mg} / \mathrm{mL}$ of RNA of total volume of tran- 


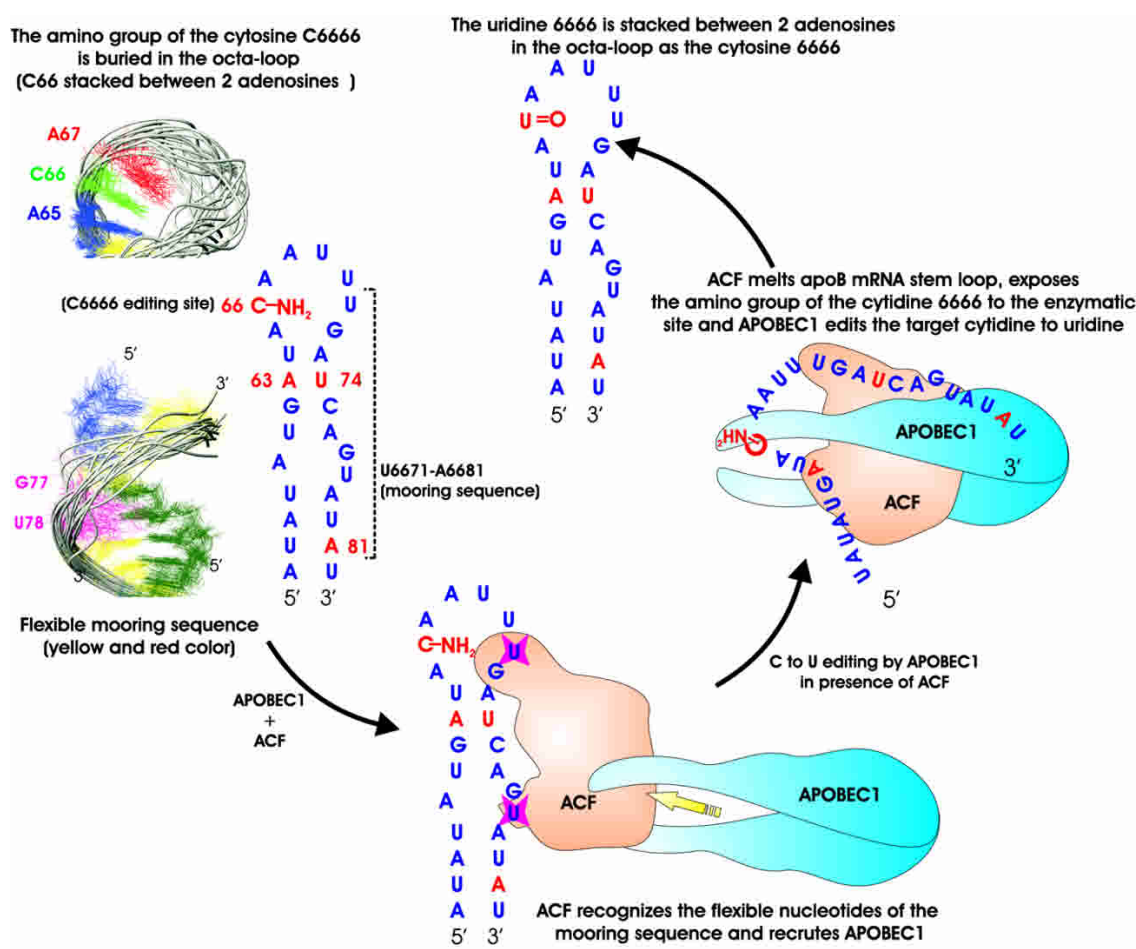

FIGURE 13. Mechanism proposed for apoB mRNA editing by APOBEC1 in presence of ACF. Site-specific labeled RNA nucleotides studied in Figure 12 are indicated in red. The red stars indicate the nucleotides proposed to be first recognized by ACF based on NMR data at $25^{\circ} \mathrm{C}$.

scription). The labeled nucleotides were supplied by Spectra Stable Isotopes. A-labeled RNA, U-labeled RNA, GC-labeled RNA, and fully labeled RNA were synthesized for apoB mRNA. Fully labeled RNA was prepared for the apoB mRNA edited (U6666). The final concentrations of labeled and unlabeled RNA were between 1.0 and $1.5 \mathrm{mM}$.

\section{Protein preparation and complex formation}

\section{ACF34 expression and purification}

E. coli strain BL21(DE3) transfected with the expression vector pET14 (Novagen, Inc.) with the ACF34 gene inserted was inoculated from a glycerol stock into M9 media. The cultures were incubated at $37^{\circ} \mathrm{C}$ until $\mathrm{OD}_{590}$ was $\sim 0.5-0.6$. Expression was induced by the addition of $1 \mathrm{mM}$ IPTG and harvested after $12 \mathrm{~h}$. The cells were resuspended in $20 \mathrm{~mL} / \mathrm{L}$ of cold $\left(4^{\circ} \mathrm{C}\right)$ lysis buffer $(50$ $\mathrm{mM} \mathrm{NaH} \mathrm{PO}_{4}, 300 \mathrm{mM} \mathrm{NaCl}, 10 \mathrm{mM}$ imidazole, $0.25 \%$ Tween 20, $0.1 \mathrm{mM}$ EDTA at $\mathrm{pH} 8.0$ ) and then lysed by sonication. The lysates were cleared by centrifugation at 20,000g. Five milliliters NiNTA resin (Qiagen) per $40 \mathrm{~mL}$ lysate were then added to the cleared lysates and incubated at $4^{\circ} \mathrm{C}$ overnight with gentle agitation. The resin was then transferred to a column and washed with $8 \times$ column volume of lysis buffer. The protein was then eluted from the column with buffers containing $50 \mathrm{mM} \mathrm{Ha}_{2} \mathrm{HPO}_{4}, 600$ $\mathrm{mM} \mathrm{NaCl}(\mathrm{pH} 8.0)$, and a step gradient of imidazole with imidazole concentrations of 30, 40, 50, 100, 150, and $250 \mathrm{mM}$. Fractions containing pure protein were combined and concentrated with an Amicon concentrator using a polyethersulfone membrane
(NMWL 5000) until the protein concentration was between 0.5 and $1 \mathrm{mM}$. The buffer was then exchanged for $29 \mathrm{mM}$ $\mathrm{Na}_{2} \mathrm{HPO}_{4}, 170 \mathrm{mM} \mathrm{NaCl}(\mathrm{pH} 8.0$ ) by dialysis and the protein was further concentrated by centrifugation in a microcon concentrator until final NMR concentration (2 $\mathrm{mM}$ ) was reached. The RNAse activity was checked by a fluorometric test RNase assay (Ambion).

\section{Complex formation between ACF34 and the 31-nt stem-loop}

\begin{abstract}
${ }^{15} \mathrm{~N}$ labeled ACF34 was added in successive amounts to a $1 \mathrm{mM}$ sample of SL31 up to a ratio 1:1. Because the linewidth of the amide resonances was very broad, the complex was dialyzed overnight against a low salt concentration phosphate buffer (20 $\mathrm{mM} \mathrm{NaCl}$ at $\mathrm{pH} 8.0$ ). The resulting spectra at $25^{\circ} \mathrm{C}$ had better spectral dispersion and sharper linewidth. The temperature was then raised in steps; significant improvement of the protein resonance linewidths was clearly observed at $37^{\circ} \mathrm{C}$ and $42^{\circ} \mathrm{C}$.
\end{abstract}

\section{UV cross-linking experiments}

Site-specifically ${ }^{32} \mathrm{P}$-labeled substrates for cross-linking were produced by the ligation of 5' and 3' RNAs (Moore and Sharp 1992). UV cross-linking studies were carried out as described previously (Navaratnam et al. 1993). APOBEC1 and/or ACF were preincubated with the RNA at $30^{\circ} \mathrm{C}$ for $20 \mathrm{~min}$ prior to UV cross-linking. Cross-linking data were quantified by laser densitometric scanning (Storm Phosphorimager, Molecular Dynamics) and were analyzed by ImageQuant software.

\section{In vitro editing assay}

In vitro editing assays were carried out at $30^{\circ} \mathrm{C}$ as previously described (Navaratnam et al. 1995). Mutations were performed by changing 6-nt sections to the complementary sequence of apoB mRNA. APOBEC1 and ACF purifications were essentially done as described before (Blanc et al. 2001a; Jarmuz et al. 2002). TLC editing assays were carried out essentially as described by Miyamoto et al. (2002), but with the 31-nt apoB mRNA substrate.

\section{NMR spectroscopy}

NMR spectra were acquired either at $500 \mathrm{MHz}$ equipped with a cryo-probe, $600 \mathrm{MHz}, 800 \mathrm{MHz}$, or $900 \mathrm{MHz}$ on Bruker DRX spectrometers. Nearly complete ${ }^{1} \mathrm{H},{ }^{13} \mathrm{C}$, and ${ }^{15} \mathrm{~N}$ assignments were made for apoB mRNA using a combination of homonuclear and ${ }^{13} \mathrm{C}$ and/or ${ }^{15} \mathrm{~N}$ heteronuclear NMR experiments. $\left({ }^{1} \mathrm{H}-{ }^{1} \mathrm{H}\right)$ NOESY in $\mathrm{H}_{2} \mathrm{O}$ at $278 \mathrm{~K}$ and in $\mathrm{D}_{2} \mathrm{O}$ at $303 \mathrm{~K}$, natural abundance $\left({ }^{1} \mathrm{H}-{ }^{13} \mathrm{C}\right)$ HSQC, $\left({ }^{1} \mathrm{H}-{ }^{1} \mathrm{H}\right)$ TOCSY $\left(\tau_{\mathrm{m}}=50 \mathrm{msec}\right)$ experiments were acquired on the three unlabeled RNAs. The sugar pucker 
conformations were determined with a DQF-COSY experiment. Most of the aromatic and $\mathrm{H}^{\prime}{ }^{\prime}$ protons were assigned by sequential assignment based on the helical structure using standard NMR experiments performed on unlabeled samples (Wüthrich 1986; Van Buuren and Wijmenga 1998). Assignment ambiguities were elucidated with the $3 \mathrm{D}\left({ }^{1} \mathrm{H}_{-}{ }^{13} \mathrm{C}\right)$ NOESY-HSQC and $\left({ }^{1} \mathrm{H}_{-}{ }^{13} \mathrm{C}\right)$ CT-HSQC performed on each specific ${ }^{13} \mathrm{C}$ - and ${ }^{15} \mathrm{~N}$-labeled sample. Sugar protons were assigned with the combination of $3 \mathrm{D}$ HCCH-TOCSY and 3D $\left({ }^{1} \mathrm{H}^{13} \mathrm{C}\right)$ NOESY-HSQC spectra (Wüthrich 1986; Van Buuren and Wijmenga 1998). The NOE build-up curve was made with 40-, 100-, 200-, 250-, and 300-msec mixing times to estimate NOE distances from the integrated peak volumes of the 2D NOESY spectra. Assignments were made for all guanosine and uracil imino proton signals observed at $5^{\circ} \mathrm{C}$ except for the loop residues U69, U70, U71, G72, and G77 that could not be assigned unambiguously due to the lack of sequential NOEs and the fast proton exchange with the solvent. Imino uracil protons within the stem were confirmed with an $\mathrm{H} 3$ imino- $\mathrm{H} 5$ correlation experiment (Wohnert et al. 1999) and on the basis of their characteristic downfield chemical shift and a strong NOE to an adenine $\mathrm{H} 2$, indicative of a uracil moiety involved in an A-U base pair. Imino protons of U78 and U61 residues did not give any crosspeak correlation in this $\mathrm{H} 3$ imino-H5 correlation experiment, indicative of a fast proton exchange with water. Also, the assignment of the imino protons in the stem became straightforward with the analysis of the NOESY spectrum in $\mathrm{H}_{2} \mathrm{O}$ of apoB mRNA without G77; G62 imino proton showed clear correlations with the imino protons of U61 and U74. Detection of $\mathrm{NH} \cdots \mathrm{N}$ hydrogen bonding via scalar coupling was performed using the $J(N, N)$ HNN-COSY experiment (Dingley and Grzesiek 1998).

For the protein-RNA complex study, series of proton $1 \mathrm{D}\left({ }^{1} \mathrm{H}-\right.$ $\left.{ }^{1} \mathrm{H}\right)$ TOCSY $\left(\tau_{\mathrm{m}}=50 \mathrm{msec}\right)$ and $\left({ }^{1} \mathrm{H}-{ }^{15} \mathrm{~N}\right)$ HSQC were acquired at different stages of the titration and after complex dialysis in low salt $(20 \mathrm{mM} \mathrm{NaCl})$ at different temperatures (from $20^{\circ} \mathrm{C}$ to $50^{\circ} \mathrm{C}$ ). Water flip-back pulse, pulsed-field gradient, watergate, or presaturation methods were used for water suppression. All homonuclear and heteronuclear experiments were collected using the StatesTPPI method. Heteronuclear decoupling during acquisition was achieved with either WALTZ-16 (for ${ }^{15} \mathrm{~N}$ ) or GARP (for ${ }^{13} \mathrm{C}$ ) modulation. All data were processed using the Bruker XWIN NMR software and analyzed with the NMR assignment programs Sparky (http://www.cgl.ucsf.edu/home/sparky/) and Xeasy (http:// www.mol.biol.ethz.ch/wuthrich/software).

\section{Structure calculations}

NOE intensities were calibrated with NOE build-up curves. The pyrimidines $\mathrm{H} 5-\mathrm{H} 6$ cross-peak intensities were used as a distance calibration (2.5 $\AA$ ). Upper-limit distance restraints of 2.5, 3.7, 4.5, and $6 \AA$ were used based on observed NOEs of strong, medium, weak, and very weak intensities, respectively. Upper limit restraints of $5 \AA$ were used for aromatic-aromatic interresidue NOEs. The NMR restraints of the stem including the internal loop were identical for both RNAs. All structure calculations were performed with additional restraints to enforce Watson-Crick hydrogen bonds for G54-C84, G55-C83, A56-U82, U57-A81, A58-U80, U59-A79, U61-A76, G62-C75, A63-U74, and U64-A73 base pairs (two restraints per hydrogen bond). In addition, loose dihedral angle restraints $\left( \pm 20^{\circ} \mathrm{C}\right)$ were employed only for the phosphodiester linkages of the first five base pairs (G54-U59 and A79-C84)
(Wuttke et al. 1997). Dihedral angle restraints $\delta$ for the ribose moieties were estimated from analysis of the $\mathrm{H} 1^{\prime}-\mathrm{H} 2^{\prime}$ coupling constants $\left(\mathrm{J}_{\mathrm{H}^{\prime}-\mathrm{H} 2^{\prime}}\right)$ in the DQF-COSY spectrum. All ribose puckers of the loop nucleotides and G54, U64, U78, and C84 were restrained in the range of the $\mathrm{C} 2^{\prime}+\mathrm{C}^{\prime}$ '-endo conformations during molecular dynamics $\left(65^{\circ}<\delta<180^{\circ}\right)$ since the $\mathrm{H} 1^{\prime}-\mathrm{H} 2^{\prime}$ coupling constants were between $6 \mathrm{~Hz}$ and $8 \mathrm{~Hz}$. The other nucleotides with no COSY and TOCSY cross-peaks between the $\mathrm{H} 1^{\prime}-\mathrm{H} 2^{\prime}$ protons $\left(\mathrm{J}_{\mathrm{H}^{\prime}-\mathrm{H} 2^{\prime}}<3 \mathrm{~Hz}\right)$ were constrained $\mathrm{C}^{\prime}$ endo $\left(\delta=85 \pm 20^{\circ}\right)$. For both RNAs, two sets of structure calculation were run, "G72 anti" and "G72 syn" because not all distance constraints involving G72 could be fulfilled with one single calculation, similar to the Nucleolin binding RNA (Bouvet et al. 2001). Two intra- and internucleotide constraints compatible with the G72 anti position were introduced in the first structure calculation set: intra G72 H8-H1', G72 H8-H3' constraint distances of $3.7 \AA$ and $3.0 \AA$ and sequential G72 H8-U71 H2', G72 H8-U71 H3' constraint distances of $3.7 \AA$ and $4.5 \AA$. In the second set, only the strong intra $\mathrm{H} 8-\mathrm{H} 1^{\prime}$ constraint typical of the G72 syn position (set to $3.0 \AA$ ) was kept for the G72 constraints. For the edited apoB mRNA, we included an additional very weak internucleotide constraint ( $6 \AA$ ) between $\mathrm{A} 65 \mathrm{H} 2$ and G72 H8 only compatible with the syn conformation. We did not constrain $\chi$ angles. Hydrogenbond restraints identified on the basis of the NOE cross-peak patterns for the nonexchangeable and exchangeable imino protons were included for the Watson-Crick base pairs of the A-helical stem (two distances per hydrogen bond). Structures were first calculated with the program DYANA using NOE distance, hydrogen-bond, and dihedral angle restraints (Guntert et al. 1997). These artificial dihedral angle restraints do not exert any force on the final structures, but are needed to efficiently converge to a minimum where all other restraints can be satisfied. The final structure refinement was performed with AMBER version 7.0 (http://www. nersc.gov/nusers/resources/software/apps/chemistry/ amber/). Structures were calculated in vacuo condition from 50 random structures according to the protocol previously published (Stefl et al. 2001; Padrta et al. 2002). Chirality constraints were included in the calculation protocol for the randomized structures and the final structures to avoid any atom flipping during the heating step. The relative weightings of the "improper" torsion (IMPROP variable), bond energy (BOND variable), torsion energy (TORSION variable), and valence angle energy terms (ANGLE variable) were adjusted, respectively, to $200,4,4$, and 4 to avoid any base distortion. The values of the force constants for the various energy terms employed for restraints are as follows: $50 \mathrm{kcal}$ $\mathrm{mol}^{-1} \AA^{-2}$ for interproton distance restraints; $500 \mathrm{kcal} \mathrm{mol}^{-1}$ $\operatorname{rad}^{-2}$ for experimental $\delta$ dihedral angle restraints, and $250 \mathrm{kcal}$ $\mathrm{mol}^{-1} \mathrm{rad}^{-2}$ for the others. The 20 structures with the lowest Amber energy were selected for the structural analysis. Molecules were visualized with MOLMOL 2K.1 software (Koradi et al. 1996).

The four ensembles of RNA structures have been deposited in the Brookhaven Protein Data Bank.

\section{ACKNOWLEDGMENTS}

We are grateful to Dr. Fred Damberger and Prof. Gerhard Wider for their assistance in the NMR instrumentation and Dr. Richard Stefl for help with the structure calculation and helpful discussions. This investigation was supported by grants from the Fondation Schlumberger pour l'Education et la Recherche (postdoc- 
toral fellowhip), the Swiss National Science Foundation (Nr. 3167098.01), and by the Roche Research Fund for Biology at the ETH Zurich to F.H.T.A.

\section{Received September 29, 2004; accepted November 19, 2004.}

\section{REFERENCES}

Anant, S., MacGinnitie, A.J., and Davidson, N.O. 1995. apobec-1, the catalytic subunit of the mammalian apolipoprotein B mRNA editing enzyme, is a novel RNA-binding protein. J. Biol. Chem. 270: 14762-14767.

Backus, J.W. and Smith, H.C. 1992. Three distinct RNA sequence elements are required for efficient apolipoprotein B (apoB) RNA editing in vitro. Nucleic Acids Res. 20: 6007-6014.

Blanc, V., Henderson, J.O., Kennedy, S., and Davidson, N.O. 2001a. Mutagenesis of apobec-1 complementation factor reveals distinct domains that modulate RNA binding, protein-protein interaction with apobec-1, and complementation of $\mathrm{C}$ to U RNA-editing activity. J. Biol. Chem. 276: 46386-46393.

Blanc, V., Navaratnam, N., Henderson, J.O., Anant, S., Kennedy, S., Jarmuz, A., Scott, J., and Davidson, N.O. 2001b. Identification of GRY-RBP as an apolipoprotein B RNA-binding protein that interacts with both apobec- 1 and apobec-1 complementation factor to modulate C to U editing. J. Biol. Chem. 276: 10272-10283.

Bostrom, K., Lauer, S.J., Poksay, K.S., Garcia, Z., Taylor, J.M., and Innerarity, T.L. 1989. Apolipoprotein B48 RNA editing in chimeric apolipoprotein EB mRNA. J. Biol. Chem. 264: 15701-15708.

Bouvet, P., Allain, F.H., Finger, L.D., Dieckmann, T., and Feigon, J. 2001. Recognition of pre-formed and flexible elements of an RNA stem-loop by nucleolin. J. Mol. Biol. 309: 763-775.

Chen, S.H., Habib, G., Yang, C.Y., Gu, Z.W., Lee, B.R., Weng, S.A., Silberman, S.R., Cai, S.J., Deslypere, J.P., Rosseneu, M., et al. 1987. Apolipoprotein B-48 is the product of a messenger RNA with an organ-specific in-frame stop codon. Science 238: 363-366.

Chen, S.H., Li, X.X., Liao, W.S., Wu, J.H., and Chan, L. 1990. RNA editing of apolipoprotein B mRNA. Sequence specificity determined by in vitro coupled transcription editing. J. Biol. Chem. 265: 6811-6816.

Chester, A., Weinreb, V., Carter Jr., C.W., and Navaratnam, N. 2004. Optimization of apolipoprotein B mRNA editing by APOBEC1 apoenzyme and the role of its auxiliary factor, ACF. RNA 10: 13991411.

Chowdhury, S., Ragaz, C., Kreuger, E., and Narberhaus, F. 2003. Temperature-controlled structural alterations of an RNA thermometer. J. Biol. Chem. 278: 47915-47921.

Davies, M.S., Wallis, S.C., Driscoll, D.M., Wynne, J.K., Williams, G.W., Powell, L.M., and Scott, J. 1989. Sequence requirements for apolipoprotein B RNA editing in transfected rat hepatoma cells. J. Biol. Chem. 264: 13395-13398.

Dingley, A.J. and Grzesiek, S. 1998. Direct observation of hydrogen bonds in nucleic acid base pairs by internucleotide ${ }^{2} \mathrm{~J}_{\mathrm{NN}}$ couplings. J. Am. Chem. Soc. 120: 8293-8297.

Driscoll, D.M. and Zhang, Q. 1994. Expression and characterization of p27, the catalytic subunit of the apolipoprotein B mRNA editing enzyme. J. Biol. Chem. 269: 19843-19847.

Driscoll, D.M., Wynne, J.K., Wallis, S.C., and Scott, J. 1989. An in vitro system for the editing of apolipoprotein B mRNA. Cell 58: $519-525$.

Driscoll, D.M., Lakhe-Reddy, S., Oleksa, L.M., and Martinez, D. 1993. Induction of RNA editing at heterologous sites by sequences in apolipoprotein B mRNA. Mol. Cell. Biol. 13: 7288-7294.

Giannoni, F., Bonen, D.K., Funahashi, T., Hadjiagapiou, C., Burant, C.F., and Davidson, N.O. 1994. Complementation of apolipoprotein B mRNA editing by human liver accompanied by secretion of apolipoprotein B48. J. Biol. Chem. 269: 5932-5936.

Greeve, J., Altkemper, I., Dieterich, J.H., Greten, H., and Windler, E. 1993. Apolipoprotein B mRNA editing in 12 different mammalian species: Hepatic expression is reflected in low concentrations of apoB-containing plasma lipoproteins. J. Lipid Res. 34: 1367-1383.

Guntert, P., Mumenthaler, C., and Wuthrich, K. 1997. Torsion angle dynamics for NMR structure calculation with the new program DYANA. J. Mol. Biol. 273: 283-298.

Hadjiagapiou, C., Giannoni, F., Funahashi, T., Skarosi, S.F., and Davidson, N.O. 1994. Molecular cloning of a human small intestinal apolipoprotein B mRNA editing protein. Nucleic Acids Res. 22: 1874-1879.

Hersberger, M. and Innerarity, T.L. 1998. Two efficiency elements flanking the editing site of cytidine 6666 in the apolipoprotein B mRNA support mooring-dependent editing. J. Biol. Chem. 273: 9435-9442.

Hersberger, M., Patarroyo-White, S., Arnold, K.S., and Innerarity, T.L. 1999. Phylogenetic analysis of the apolipoprotein B mRNA-editing region. Evidence for a secondary structure between the mooring sequence and the $3^{\prime}$ efficiency element. J. Biol. Chem. 274: 34590-34597.

Innerarity, T.L., Boren, J., Yamanaka, S., and Olofsson, S.O. 1996. Biosynthesis of apolipoprotein B48-containing lipoproteins. Regulation by novel post-transcriptional mechanisms. J. Biol. Chem. 271: 2353-2356.

Jarmuz, A., Chester, A., Bayliss, J., Gisbourne, J., Dunham, I., Scott, J., and Navaratnam, N. 2002. An anthropoid-specific locus of orphan $\mathrm{C}$ to U RNA-editing enzymes on chromosome 22. Genomics 79: 285-296.

Koradi, R., Billeter, M., and Wuthrich, K. 1996. MOLMOL: A program for display and analysis of macromolecular structures. J. Mol. Graph. 14: 29-32, 51-55.

Lau, P.P., Xiong, W.J., Zhu, H.J., Chen, S.H., and Chan, L. 1991. Apolipoprotein B mRNA editing is an intranuclear event that occurs posttranscriptionally coincident with splicing and polyadenylation. J. Biol. Chem. 266: 20550-20554.

MacGinnitie, A.J., Anant, S., and Davidson, N.O. 1995. Mutagenesis of apobec-1, the catalytic subunit of the mammalian apolipoprotein $B$ mRNA editing enzyme, reveals distinct domains that mediate cytosine nucleoside deaminase, RNA binding, and RNA editing activity. J. Biol. Chem. 270: 14768-14775.

Mehta, A. and Driscoll, D.M. 2002. Identification of domains in apobec-1 complementation factor required for RNA binding and apolipoprotein-B mRNA editing. RNA 8: 69-82.

Mehta, A., Kinter, M.T., Sherman, N.E., and Driscoll, D.M. 2000. Molecular cloning of apobec-1 complementation factor, a novel RNA-binding protein involved in the editing of apolipoprotein B mRNA. Mol. Cell. Biol. 20: 1846-1854.

Miyamoto, T., Obokata, J., and Sugiura, M. 2002. Recognition of RNA editing sites is directed by unique proteins in chloroplasts: Biochemical identification of cis-acting elements and trans-acting factors involved in RNA editing in tobacco and pea chloroplasts. Mol. Cell. Biol. 22: 6726-6734.

Moore, M.J. and Sharp, P.A. 1992. Site-specific modification of premRNA: The 2'-hydroxyl groups at the splice sites. Science 256: 992-997.

Nakamuta, M., Oka, K., Krushkal, J., Kobayashi, K., Yamamoto, M., Li, W.H., and Chan, L. 1995. Alternative mRNA splicing and differential promoter utilization determine tissue-specific expression of the apolipoprotein B mRNA-editing protein (Apobec1) gene in mice. Structure and evolution of Apobec1 and related nucleoside/ nucleotide deaminases. J. Biol. Chem. 270: 13042-13056.

Navaratnam, N., Shah, R., Patel, D., Fay, V., and Scott, J. 1993. Apolipoprotein B mRNA editing is associated with UV crosslinking of proteins to the editing site. Proc. Natl. Acad. Sci. 90: 222-226.

Navaratnam, N., Bhattacharya, S., Fujino, T., Patel, D., Jarmuz, A.L., and Scott, J. 1995. Evolutionary origins of apoB mRNA editing: Catalysis by a cytidine deaminase that has acquired a novel RNAbinding motif at its active site. Cell 81: 187-195.

Navaratnam, N., Fujino, T., Bayliss, J., Jarmuz, A., How, A., Richardson, N., Somasekaram, A., Bhattacharya, S., Carter, C., and Scott, J. 1998. Escherichia coli cytidine deaminase provides a molecular model for ApoB RNA editing and a mechanism for RNA substrate 
recognition. J. Mol. Biol. 275: 695-714.

Padrta, P., Stefl, R., Kralik, L., Zidek, L., and Sklenar, V. 2002. Refinement of d(GCGAAGC) hairpin structure using one- and twobond residual dipolar couplings. J. Biomol. NMR 24: 1-14.

Powell, L.M., Wallis, S.C., Pease, R.J., Edwards, Y.H., Knott, T.J., and Scott, J. 1987. A novel form of tissue-specific RNA processing produces apolipoprotein-B48 in intestine. Cell 50: 831-840.

Price, S.R., Oubridge, C., Varani, G., and Nagai, K. 1998. Preparation of RNA-protein complexes for X-ray crystallography and NMR. Oxford University Press, Oxford, UK.

Richardson, N., Navaratnam, N., and Scott, J. 1998. Secondary structure for the apolipoprotein B mRNA editing site. Au-binding proteins interact with a stem loop. J. Biol. Chem. 273:3170731717.

Shah, R.R., Knott, T.J., Legros, J.E., Navaratnam, N., Greeve, J.C., and Scott, J. 1991. Sequence requirements for the editing of apolipoprotein B mRNA. J. Biol. Chem. 266: 16301-16304.

Sowden, M.P., Lehmann, D.M., Lin, X., Smith, C.O., and Smith HC. 2004. Identification of novel alternative splice variants of APOBEC-1 complementation factor with different capacities to support apolipoprotein B mRNA editing. J. Biol. Chem. 279: 197-206.

Stefl, R., Trantirek, L., Vorlickova, M., Koca, J., Sklenar, V., and Kypr, J. 2001. A-like guanine-guanine stacking in the aqueous DNA duplex of d(GGGGCCCC). J. Mol. Biol. 307: 513-524.

Teng, B. and Davidson, N.O. 1992. Evolution of intestinal apolipoprotein B mRNA editing. Chicken apolipoprotein B mRNA is not edited, but chicken enterocytes contain in vitro editing enhancement factor(s). J. Biol. Chem. 267: 21265-21272.

Teng, B., Burant, C.F., and Davidson, N.O. 1993. Molecular cloning of an apolipoprotein B messenger RNA editing protein. Science 260: $1816-1819$.
Teng, B., Blumenthal, S., Forte, T., Navaratnam, N., Scott, J., Gotto Jr., A.M., and Chan, L. 1994. Adenovirus-mediated gene transfer of rat apolipoprotein B mRNA-editing protein in mice virtually eliminates apolipoprotein B-100 and normal low density lipoprotein production. J. Biol. Chem. 269: 29395-29404.

Van Buuren, B.N.M. and Wijmenga, S.S. 1998. The use of NMR methods for conformational studies of nucleic acids. Progr. NMR Spectrosc. 32: 287-387.

Wohnert, J., Ramachandran, R., Gorlach, M., and Brown, L.R. 1999. Triple-resonance experiments for correlation of $\mathrm{H} 5$ and exchangeable pyrimidine base hydrogens in (13)C,(15)N-labeled RNA. J. Magn. Reson. 139: 430-433.

Wüthrich, K. 1986. NMR of proteins and nucleic acids. John Wiley \& Sons, New York.

Wuttke, D.S., Foster, M.P., Case, D.A., Gottesfeld, J.M., and Wright, P.E. 1997. Solution structure of the first three zinc fingers of TFIIIA bound to the cognate DNA sequence: Determinants of affinity and sequence specificity. J. Mol. Biol. 273: 183-206.

Yamanaka, S., Poksay, K.S., Balestra, M.E., Zeng, G.Q., and Innerarity, T.L. 1994. Cloning and mutagenesis of the rabbit ApoB mRNA editing protein. A zinc motif is essential for catalytic activity, and noncatalytic auxiliary factor(s) of the editing complex are widely distributed. J. Biol. Chem. 269: 21725-21734.

Yamanaka, S., Poksay, K.S., Driscoll, D.M., and Innerarity, T.L. 1996. Hyperediting of multiple cytidines of apolipoprotein B mRNA by APOBEC-1 requires auxiliary protein(s) but not a mooring sequence motif. J. Biol. Chem. 271: 11506-11510.

Zanier, K., Luyten, I., Crombie, C., Muller, B., Schumperli, D., Linge, J.P., Nilges, M., and Sattler, M. 2002. Structure of the histone mRNA hairpin required for cell cycle regulation of histone gene expression. RNA 8: 29-46. 